"This is the peer reviewed version of the following article: ChemSusChem 2016, 9, 749-755, which has been published in final form at doi.org/10.1002/cssc.201501463|. This article may be used for non-commercial purposes in accordance with Wiley Terms and Conditions for Self-Archiving published at http://olabout.wiley.com/WileyCDA/Section/id-820227.html." 


\title{
Cavitand based Polyphenols as Highly Reactive Organocatalysts for the Coupling of Carbon Dioxide and Oxiranes
}

\author{
Luis Martínez-Rodríguez, ${ }^{[a]}$ Javier Otalora Garmilla ${ }^{[a]}$ and Arjan W. Kleij ${ }^{*[a] b]}$
}

\begin{abstract}
Various cavitand based polyphenols were prepared from cheap and accessible aldehyde and resorcinol/pyrogallol reagents giving their respective resorcin[4]- or pyrogallol[4]arenes. The preorganization of the phenolic units allows for intra- and intermolecular hydrogen bond $(\mathrm{HB})$ networks affecting both the reactivity and stability of these HB donor catalysts. Unexpectedly, we found that resorcin[4]arenes show cooperative catalysis behavior compared to parent resorcinol in the catalytic coupling of epoxides and $\mathrm{CO}_{2}$ with significantly higher turnover. At elevated reaction temperatures, the resorcin[4]arene based catalyst $\mathbf{3 d}$ displays the best catalytic performance with both very high turnover numbers and frequencies combining increased reactivity and stability compared to pyrogallol, and ample substrate scope. This type of polyphenol structure thus illustrates the importance of a new, highly competitive organocatalyst design for devising sustainable $\mathrm{CO}_{2}$ conversion processes.
\end{abstract}

of efficient catalyst systems based on binary or bifunctional systems comprising of azaphosphatranes, ${ }^{[8]}$ polyphenols, ${ }^{[9]}$ phosphonium or ammonium alcohols, ${ }^{[10]}$ silane diols ${ }^{[11]}$ and fluorinated alcohols. ${ }^{[12]}$ Parallel to these activities other promising organocatalytic systems have been recently communicated presenting new catalyst designs based on the host-guest complexation of nucleophilic reagents, ${ }^{[13]}$ the use of phosphorus ylides ${ }^{[14]}$ and hydroxy-functionalized mono- and bis-imidazolium bromides. ${ }^{[15]}$

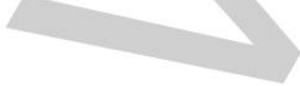

Resorcinol/ Pyrogallol<smiles>[X]c1c(O)cccc1O</smiles>

1a: $X=H$

$1 \mathrm{~b}: \mathrm{X}=\mathrm{OH}$

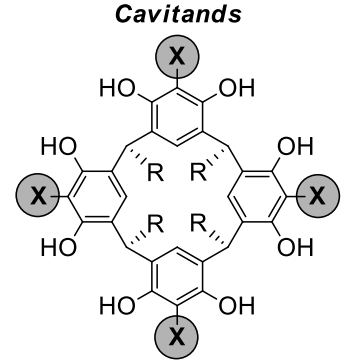

3: $\mathrm{X}=\mathrm{H}, \mathrm{OH} ; \mathrm{R}=$ alkyl, aryl

conversion is the design of appropriate catalytic systems that show improved reactivity and selectivity behavior. ${ }^{[1]}$ Up to date, most of the attention in the area of $\mathrm{CO}_{2}$ catalysis has been focused on (homogeneous) catalysts based on metal complexes of various kinds showing in a few cases high reactivity and unusual scope and/or selectivity. ${ }^{[2]}$ Metal catalysts based on abundant metals such as $\mathrm{Zn},{ }^{[3]} \mathrm{Fe},{ }^{[4]} \mathrm{Al},{ }^{[5]}$ and $\mathrm{Co}^{[6]}$ have by far received most of the attention allowing for significant evolution in both catalyst design as well as improving the product portfolio that can be accessed from $\mathrm{CO}_{2}$ representing a renewable and cheap carbon feed stock for chemical synthesis.

Organocatalysis has recently appeared on the radar of synthetic chemists representing a sustainable alternative for metal based approaches in $\mathrm{CO}_{2}$ conversion catalysis. ${ }^{[7]}$ In particular, the catalytic coupling of epoxides and $\mathrm{CO}_{2}$ has been studied extensively and can be regarded as a benchmark process for new catalyst development in non-reductive $\mathrm{CO}_{2}$ couplings. Progress in this area has been considerable with the development

\footnotetext{
[a] L. Martínez-Rodríguez, J. Otalora Garmilla, Prof. Dr. A. W. Klei Institute of Chemical Research of Catalonia (ICIQ)

The Barcelona Institute of Science and Technology Av. Països Catalans 16, 43007 Tarragona (Spain) E-mail: akleij@iciq.es

[b] Prof. Dr. A. W. Kleij

Catalan Institute of Research and Advanced Studies (ICREA) Pg. Lluís Companys 23, 08010 Barcelona (Spain)
}

Supporting information for this article is given via a link at the end of the document.
Figure 1. Schematic structures of resorcinol (1a), pyrogallol (1b), tannic acid (2) and cavitand based polyphenols (3).

We have become interested in the use of (natural) polyphenols such as pyrogallol and tannic acid (see Figure 1; 1b and 2) for the conversion of epoxides through hydrogen bond (HB) activation. Their transformation into cyclic carbonates in the presence of $\mathrm{CO}_{2}$ takes advantage of the extended $\mathrm{HB}$ network that arises upon activation of the epoxide towards the formation of key intermediates, and consequently lower kinetic barriers 
allowed for either low temperature conversions $\left(45^{\circ} \mathrm{C}\right)^{[9 b, c]}$ or the use of reduced polyphenol loading for effective catalytic turnover. ${ }^{\left[{ }^{[a]}\right.}$ Nonetheless, there are still challenges to be met upon using such polyphenols as at higher reaction temperatures (i.e., $80^{\circ} \mathrm{C}$ ) some catalyst degradation through deprotonation and formation of relatively inactive phenolate groups cannot be fully avoided preventing the efficient recycling of these phenolic additives and thus restricts the total turnover number (TON). ${ }^{[9 a, c]}$

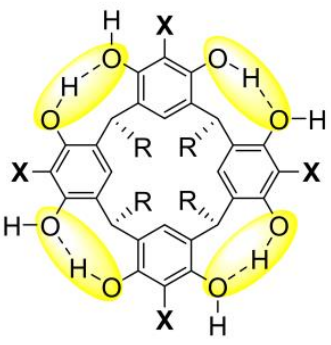

intra-molecular (monomer)

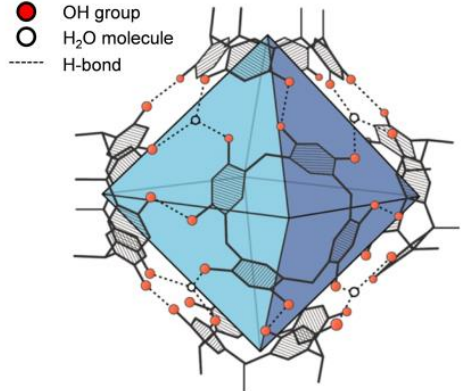

inter-molecular (hexamer)
Figure 2. Intra- and intermolecular hydrogen-bonding networks in cavitand based structures. Part of this figure has been reprinted with permission from reference 19. Copyright (2013) American Chemical Society.

\section{Results and Discussion}

Resorcin[4]arenes $\mathbf{3 a - e , ~ p y r o g a l l o l [ 4 ] a r e n e s ~} \mathbf{3} \mathbf{f}-\mathbf{i}$ and the octahydroxypyridine[4]arene 3j (Scheme 1) were prepared according to previous reported procedures (Experimental Section) and their molecular identity was established by ${ }^{1} \mathrm{H} /{ }^{13} \mathrm{C}$ NMR and mass analysis: these analyses were in accordance with the literature data (Supporting Information for details). Compounds $\mathbf{3 a}-\mathbf{3 i}$ were initially tested, in combination with $\mathrm{NBu}_{4} \mathbf{X}$ ( $\mathbf{X}=$ halide), as binary catalysts in the coupling of 1,2 epoxyhexane $4 \mathrm{a}$ and $\mathrm{CO}_{2}$ at $50^{\circ} \mathrm{C}$ using methylethyl ketone (MEK) as solvent (Table 1).

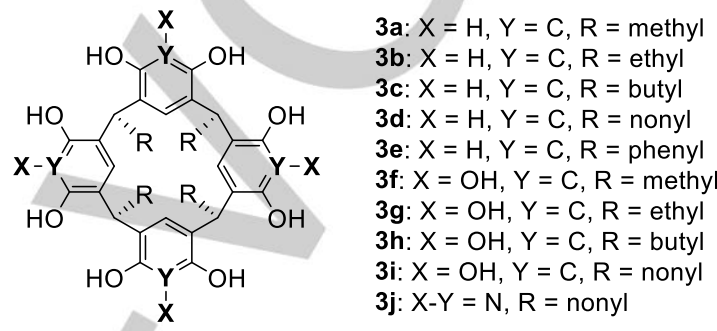

Scheme 1. Resorcin[4]arenes 3a-e, pyrogallol[4]arenes $\mathbf{3 f}-\mathbf{i}$ and the octahydroxypyridine[4]arene $\mathbf{3 j}$.
In our quest to develop thermally more robust polyphenol based catalysts while maintaining high reactivity and privileged substrate scope, we considered that cavitand structures (Figure 1 , structures 3$)^{[16]}$ may deliver the appropriate combination of activity and thermal/chemical stability. These cavitand structures, including resorcin[4]arenes $(3: \mathrm{X}=\mathrm{H})$ and pyrogallol[4]arenes (3: $X=O H$ ), give rise to pre-organized supramolecular structures, often being hexameric in nature, in solution and solid state through inter-molecular, water-assisted HB interactions (Figure 2, right) ${ }^{[17]}$ At the same time, the bowl shape of monomeric cavitand molecules is also controlled through intra-molecular HBs between adjacent resorcinol/pyrogallol units typically expressed in solvent media such as alcohols and acetonitrile (Figure 2, left). ${ }^{[18]}$ These latter, intra-molecular HB patterns suggest a similar potential for catalytic activation ${ }^{[19]}$ of epoxides compared to pyrogallol/tannic acid (Figure 1) with stabilization of key intermediate transition states through multiple HB interactions being more efficient than in the absence of such HB donors.

In this contribution we will show that cavitand based polyphenols are excellent $\mathrm{HB}$ activators in the formation of cyclic carbonates from epoxides and $\mathrm{CO}_{2}$ with unprecedented turnover numbers and frequencies. Catalytic data in combination with several control experiments support a cooperative catalytic effect when using the resorcin[4]arene systems, which also show the best combination of activity and stability at elevated temperatures. In combination with the easy access to these modular and cheap polyphenolic structures and catalytic scope, these cavitands represent a new and powerful type of organocatalyst for the conversion of $\mathrm{CO}_{2}$ into value added chemicals.

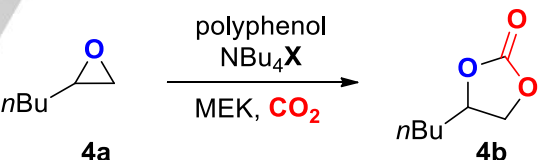

Table 1. Screening of conditions using a polyphenol/TBAX binary catalyst in the coupling of 1,2-epoxyhexane and $\mathrm{CO}_{2}$ to afford cyclic carbonate $\mathbf{4 b}$. ${ }^{[a]}$

\begin{tabular}{|c|c|c|c|c|c|c|}
\hline Entry & Polyphenol & $\begin{array}{l}\text { Amount } \\
{[\mathrm{mol} \%]}\end{array}$ & $\begin{array}{c}\mathrm{NBu}_{4} \mathrm{X} \\
{[\mathrm{mol} \%]}\end{array}$ & $\begin{array}{c}\mathrm{T} \\
{\left[{ }^{\circ} \mathrm{C}\right]}\end{array}$ & $\begin{array}{l}\text { MEK } \\
{[\mathrm{mL}]}\end{array}$ & $\begin{array}{c}\text { Yield 4b } \\
\text { [\%] }^{[\mathrm{b}]}\end{array}$ \\
\hline 1 & $3 b$ & 1.5 & I, 5.0 & 45 & 2.5 & 81 \\
\hline 2 & $3 b$ & 1.5 & I, 5.0 & 50 & 2.5 & 91 \\
\hline 3 & $3 b$ & 1.5 & I, 5.0 & 50 & 5.0 & 65 \\
\hline 4 & $3 b$ & 1.5 & $\mathrm{Cl}, 5.0$ & 50 & 2.5 & 31 \\
\hline 5 & $3 b$ & 1.5 & $\mathrm{Br}, 5.0$ & 50 & 2.5 & 65 \\
\hline 6 & - & 0 & I, 5.0 & 50 & 2.5 & 4 \\
\hline 7 & $3 b$ & 1.5 & 0 & 50 & 2.5 & 0 \\
\hline 8 & $1 a$ & 6.0 & I, 5.0 & 50 & 2.5 & 47 \\
\hline 9 & $1 a$ & 6.0 & I, 5.0 & 50 & 5.0 & 24 \\
\hline 10 & $1 b$ & 4.0 & I, 5.0 & 50 & 2.5 & 99 \\
\hline
\end{tabular}

[a] Reaction conditions: 1,2-epoxyhexane $1.0 \mathrm{mmol}, p\left(\mathrm{CO}_{2}\right)=10 \mathrm{bar}, 18 \mathrm{~h}$, polyphenol amount normalized with respect to $[\mathrm{OH}]$ groups, $p\left(\mathrm{CO}_{2}\right)^{\circ}=1.0 \mathrm{MPa}$, $18 \mathrm{~h}$. [b] NMR yields based on mesitylene as internal standard, selectivity for $\mathbf{4 b}$ was $>99 \%$. 
We first tested resorcin[4]arene $\mathbf{3 b} / \mathrm{NBu}_{4} \mathrm{l}$ as a binary catalyst for the synthesis of organic carbonates from epoxides and $\mathrm{CO}_{2}$ under conditions closely related to those previously probed for a binary pyrogallol based system (entry 1 ). ${ }^{[9 \mathrm{cc}]}$ At $45^{\circ} \mathrm{C}$, a NMR yield of $81 \%$ was already achieved, and raising the temperature to $50^{\circ} \mathrm{C}$ increased this yield to $91 \%$ (entry 2 ). Dilution of the reaction mixture (entry 3 ) or changing the nature of the nucleophile (entries 4 and 5) gave poorer kinetics leading to lower yields of $\mathbf{4 b}$. In the absence of $\mathbf{3 b}$ (entry $6 ; 4 \%$ ) or nucleophile (entry $7 ; 0 \%$ ) very low to no conversion of the epoxide substrate was noted showing the imperative role of both catalyst components in this coupling reaction. Comparison of the efficiency of resorcin[4]arene $\mathbf{3 b}$ (entry 2) with that of the parent building unit resorcinol 1a (entry 7) showed a much higher yield of carbonate $\mathbf{4 b}$ for the cavitand based system despite the use of a similar concentration of diphenol units. This effect was maintained under more dilute conditions (cf., entries 3 and 9). Pyrogallol 1b, a triphenol, gave virtually quantitative yield (entry $10,99 \%$ ) under these conditions. The remarkable yield of $\mathbf{4 b}$ in the presence of resorcin[4]arene $\mathbf{3 b}$ suggests a cooperative effect between the 1,3-diphenol sites in the catalytic activation of the epoxide and/or more efficient stabilization of the intermediates of the carbonate formation reaction.

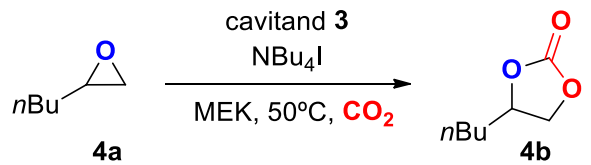

Table 2. Screening of cavitand/TBAI binary catalysts 3 in the coupling of 1,2 epoxyhexane and $\mathrm{CO}_{2}$ to afford cyclic carbonate $\mathbf{4 b}$. ${ }^{[a]}$

\begin{tabular}{|c|c|c|c|c|c|c|}
\hline Entry & Cavitand & $\begin{array}{l}\text { Amount } \\
\text { [mol \%] }\end{array}$ & $\begin{array}{c}\mathrm{NBu}_{4} \mathrm{l} \\
{[\mathrm{mol} \%]}\end{array}$ & $\begin{array}{c}\mathrm{T} \\
{\left[{ }^{\circ} \mathrm{C}\right]}\end{array}$ & $\mathrm{R}$ & $\begin{array}{c}\text { Yield 4b } \\
{ }_{[\%]^{[b]}}\end{array}$ \\
\hline 1 & $3 a$ & 1.5 & 5.0 & 50 & $\mathrm{Me}$ & 93 \\
\hline 2 & $3 b$ & 1.5 & 5.0 & 50 & Et & 91 \\
\hline 3 & $3 c$ & 1.5 & 5.0 & 50 & $\mathrm{Bu}$ & 94 \\
\hline 4 & $3 d$ & 1.5 & 5.0 & 50 & Non & 98 \\
\hline 5 & $3 e$ & 1.5 & 5.0 & 50 & $\mathrm{Ph}$ & 27 \\
\hline 6 & $3 f$ & 1.0 & 5.0 & 50 & $\mathrm{Me}$ & 78 \\
\hline 7 & $3 g$ & 1.0 & 5.0 & 50 & Et & 84 \\
\hline 8 & $3 h$ & 1.0 & 5.0 & 50 & $\mathrm{Bu}$ & 87 \\
\hline 9 & $3 \mathbf{i}$ & 1.0 & 5.0 & 50 & Non & 93 \\
\hline
\end{tabular}

[a] 1,2-epoxyhexane $1.0 \mathrm{mmol}$, polyphenol amount normalized with respect to $[\mathrm{OH}]$ groups, MEK $2.5 \mathrm{~mL}, p\left(\mathrm{CO}_{2}\right)^{\circ}=1.0 \mathrm{MPa}, 18 \mathrm{~h}$. Abbreviations: $\mathrm{Me}=$ methyl, $\mathrm{Et}=$ ethyl, $\mathrm{Bu}=n$-butyl, Non $=n$-nonyl, $\mathrm{Ph}=$ phenyl. [b] NMR yields based on mesitylene as internal standard, selectivity for $\mathbf{4 b}$ was $>99 \%$.

We then screened a series of nine cavitands $(\mathbf{3} \mathbf{a}-\mathbf{3 i}$, Scheme 1) in the coupling of 1,2-epoxyhexane $\mathbf{4 a}$ and $\mathrm{CO}_{2}$ (Table 2) to investigate the role of the pendent $\mathrm{R}$ groups. Within the series of resorcin[4]arenes $3 a-3 e$ (entries $1-5)$, the highest yield of $\mathbf{4 b}$ was achieved with $\mathbf{3 d}(\mathrm{R}=\mathrm{nonyl})$, a trend that was also observed within the series of pyrogallol[4]arenes $\mathbf{3 f - 3 i}$ (entries 6-9). ${ }^{[20]}$

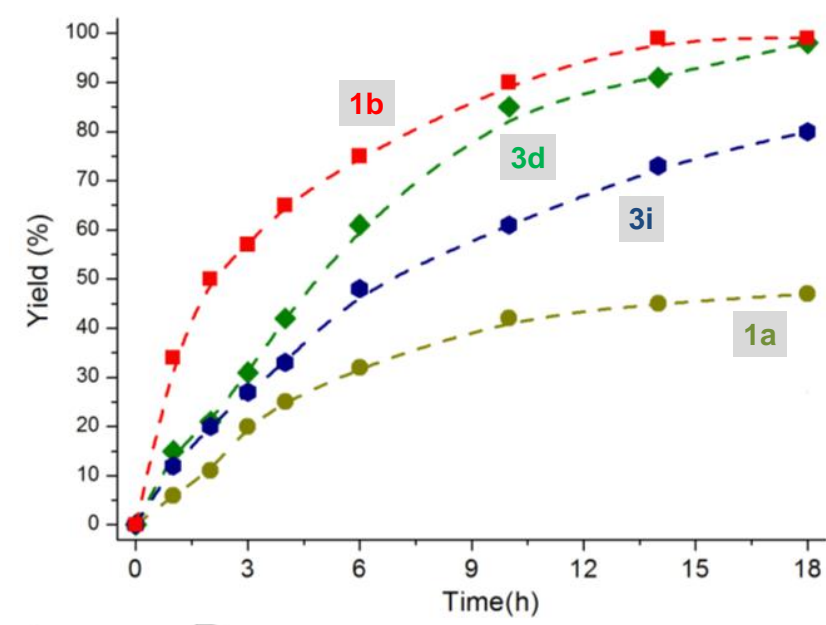

Figure 3. Comparative kinetics in the formation of carbonate $\mathbf{4 b}$ from 1,2 epoxyhexane and $\mathrm{CO}_{2}$ using resorcinol $\mathbf{1 a}$, pyrogallol $\mathbf{1 b}$, resorcin[4]arene $\mathbf{3 d}$ and pyrogallol[4]arene 3i. The polyphenol amount was normalized with respect to the $[\mathrm{OH}]$ groups. Conditions used: $4 \mathrm{~mol} \% 1 \mathrm{~b}, 5 \mathrm{~mol} \% 1 \mathrm{a}, 1.5 \mathrm{~mol} \% 3 \mathrm{~d}$ and $1.0 \mathrm{~mol} \%$ 3i. For all reactions: 1,2-epoxyhexane $1.0 \mathrm{mmol}$, NBu $45 \mathrm{~mol} \%$, MEK $2.5 \mathrm{~mL}, p\left(\mathrm{CO}_{2}\right)^{\circ}=10$ bar, $50^{\circ} \mathrm{C}$

The best-performing nonyl-substituted polyphenols $\mathbf{3} \mathbf{d}$ and $\mathbf{3 i}$ were then more closely examined and compared with the parent resorcinol $\mathbf{1 a}$ and pyrogallol $\mathbf{1} \mathbf{b}$ : the kinetic profiles of each binary catalyst (upon combining with $\mathrm{NBu}_{4}$ l) were determined (Figure 3 ). Interestingly, the pyrogallol[4]arene $\mathbf{3 i}$ shows inferior catalytic performance with respect to resorcin[4]arene $\mathbf{3 d}$. The reason for this behaviour is likely the competing self-assembly of the individual cavitand molecules of $\mathbf{3 i}$ into larger aggregates (i.e. hexamers, cf. Figure 2). Cohen et al. compared the stability of undecyl-substituted resorcin[4]arenes and pyrogallol[4]arenes. ${ }^{[21]}$ Titration studies involving these cavitand molecules demonstrated that upon increasing the polarity of the medium by adding $\mathrm{CD}_{3} \mathrm{OD}$ to a solution of the cavitand in $\mathrm{CDCl}_{3}$, the hexameric, aggregated state was fully disrupted for both types of cavitand. However, essentially much lower amounts of $\mathrm{CD}_{3} \mathrm{OD}$ were required in the case of the resorcin[4]arene in line with a stronger self-assembly behaviour of the pyrogallol[4]arene. Therefore, under the reaction conditions reported in Table 2 and Figure 3 , the poorer performance of $\mathbf{3} \mathbf{f}-\mathbf{3 i}$ compared to the resorcin[4]arene series $\mathbf{3 a} \mathbf{a} \mathbf{- 3} \mathbf{d}$ is thus explained in terms of a stronger competing self-assembly. This behaviour competes with hydrogen bonding between the epoxide and the phenolic groups, and thus slows down the reaction. In order to further support the view that competitive HB interactions can slow down the catalytic reaction, octahydroxypyridine[4]arene $\mathbf{3 j}$ (Scheme 1$)^{[22]}$ was also tested as a HB donor system in the synthesis of carbonate $\mathbf{4 b}$. The 2,6-dihydroxypyridine subunits in $\mathbf{3} \mathbf{j}$ are known to induce 
intramolecular $\mathrm{N} \cdots \mathrm{HO}$ hydrogen bonds, and the significant lower yield after $18 \mathrm{~h}(1.5 \mathrm{~mol} \%, 60 \%)$ than observed for resorcin[4]arene $3 \mathbf{d}(1.5 \mathrm{~mol} \%, 98 \%)$ is a clear testament of competitive $\mathrm{H}$-bonding. Thus, the best catalytic performance among the cavitand structures at $50^{\circ} \mathrm{C}$ is noted for $\mathbf{3 d}$.

In an effort to further increase the reactivity, the coupling of 1,2-epoxyhexane and $\mathrm{CO}_{2}$ was carried then out at $80^{\circ} \mathrm{C}$ using resorcin[4]arene $\mathbf{3 d}$, pyrogallol[4]arene $\mathbf{3 i}$ and pyrogallol $\mathbf{1 b}$ (Table 3, Figure 4). Under these conditions the nucleophilic additive $\mathrm{NBu}_{4}$ I alone produces poor catalysis (entry $1,17 \%$ yield of $\mathbf{4 b}$ ). Various combinations of cavitand/nucleophile were probed (entries 2-5) while maintaining a similar ratio between both catalyst components (ratio $\mathrm{NBu} 4 \mathrm{l} /[\mathrm{OH}]$ groups $\sim 3.3$ ). For the resorcin[4]arene $\mathbf{3 d}$ based catalyst, the conditions reported in entry 3 still produced quantitative yield of $\mathbf{4 b}$, whereas further lowering the amount of catalyst to $0.25 \mathrm{~mol} \% 3 \mathrm{~d} / 0.8 \mathrm{~mol} \% \mathrm{NBu}_{4} \mathrm{l}$ showed a modest decrease in yield to $80 \%$ (entry 4). For comparison, upon using a similar amount of catalyst derived from pyrogallol[4]arene $\mathbf{3 i}$ (cf., entries 3 and 5), a very high though not quantitative yield of $\mathbf{4 b}$ was noted. Remarkably, under these latter conditions, the pyrogallol $\mathbf{1 b}$ based catalyst produced a markedly lower yield of $\mathbf{4 b}$ (77\%; cf. entries 3 and 7$)$ showing the superior performance of the resorcin[4]- and pyrogallol[4]arene based catalysts at $80^{\circ} \mathrm{C}$.

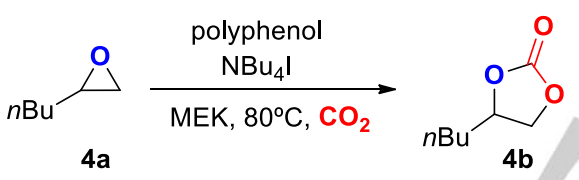

Table 3. Catalytic coupling of 1,2-epoxyhexane and $\mathrm{CO}_{2}$ at $80^{\circ} \mathrm{C}$ to afford cyclic carbonate $\mathbf{4 b}$. ${ }^{[a]}$

\begin{tabular}{cccccc}
\hline Entry & Polyphenol & $\begin{array}{c}\text { Amount } \\
{[\mathrm{mol} \%]}\end{array}$ & $\begin{array}{c}\mathrm{NBu} 4 \\
{[\mathrm{~mol} \%]}\end{array}$ & $\begin{array}{c}\mathrm{T} \\
{\left[{ }^{\circ} \mathrm{C}\right]}\end{array}$ & $\begin{array}{c}\text { Yield 4b } \\
{[\%]^{[\mathrm{b}]}}\end{array}$ \\
\hline 1 & - & 0 & 1.6 & 80 & 17 \\
2 & $\mathbf{3 d}$ & 0.75 & 2.5 & 80 & $>99$ \\
3 & $\mathbf{3 d}$ & 0.50 & 1.6 & 80 & $>99$ \\
4 & $\mathbf{3 d}$ & 0.25 & 0.8 & 80 & 80 \\
5 & $\mathbf{3 i}$ & 0.33 & 1.6 & 80 & 93 \\
6 & $\mathbf{1 b}$ & 2.0 & 3.2 & 80 & $>99$ \\
7 & $\mathbf{1 b}$ & 1.3 & 1.6 & 80 & 77 \\
8 & $\mathbf{1 b}$ & 0.66 & 0.8 & 80 & 55 \\
\hline
\end{tabular}

[a] 1,2-epoxyhexane $1.0 \mathrm{mmol}$, polyphenol amount normalized with respect to $[\mathrm{OH}]$ groups, MEK $2.5 \mathrm{~mL}, p\left(\mathrm{CO}_{2}\right)^{\circ}=1.0 \mathrm{MPa}, 18 \mathrm{~h}$. [b] NMR yields based on mesitylene as internal standard, selectivity for $\mathbf{4 b}$ was $>99 \%$.

To investigate this in more detail the full kinetic profiles for each of the catalyst systems reported in entries 3, 5 and 7 (Table 3 ) were determined (see Figure 4). The pyrogallol catalyst system reaches a plateau conversion of around $70 \%$ after $6 \mathrm{~h}$ which thereafter barely increases. This is in line with our previous results using either pyrogallol $\mathbf{1 b}$ or tannic acid $\mathbf{2}$ as catalysts components; both systems show inferior stability at this elevated temperature causing side-reactions that involve the deprotonation of the polyphenolic unit and replacement thereof by $\mathrm{NBu}_{4} \cdot{ }^{[9, \mathrm{a}, \mathrm{b}]}$ The formation of (deprotonated) phenolate groups causes a decrease in the ability to form extended HB networks as to stabilize catalytic intermediates, which results in higher kinetic barriers and thus slower reactions. Consequently, both the nucleophile and polyphenol concentration is negatively affected and the catalysis is shut down in the case of pyrogallol. On the contrary, both cavitand based catalysts based on $\mathbf{3} \mathbf{d}$ and $\mathbf{3} \mathbf{i}$ retain catalytic activity after prolonged use and therefore are more effective systems for cyclic carbonate preparation under elevated temperature conditions with $\mathbf{3} \mathbf{d}$ performing slightly better than $\mathbf{3 i}$ in the reported time span. Importantly, comparing the $\mathrm{p} K_{\mathrm{a}}$ values of resorcinol 1a $(9.20)^{[23]}$ and pyrogallol $\mathbf{1 b}(9.01)^{[24]}$ shows that the pyrogallol unit is more acidic and likely to undergo deprotonation more facilely. This is likely causing a (much) shorter lifetime of the catalyst whereas the resorcin[4]arene based system $\mathbf{3 d}$ shows comparatively a longer lifetime. This results in better potential for obtaining higher turnover numbers at elevated reaction temperatures. Interestingly, the preorganization of less active resorcinol units (cf., Figure $3, \mathbf{1 a}$ versus $\mathbf{1 b}$ ) in the cavitand significantly increases their catalytic potential as compared with the pyrogallol based one underlining the importance of the catalyst structure for effective turnover.

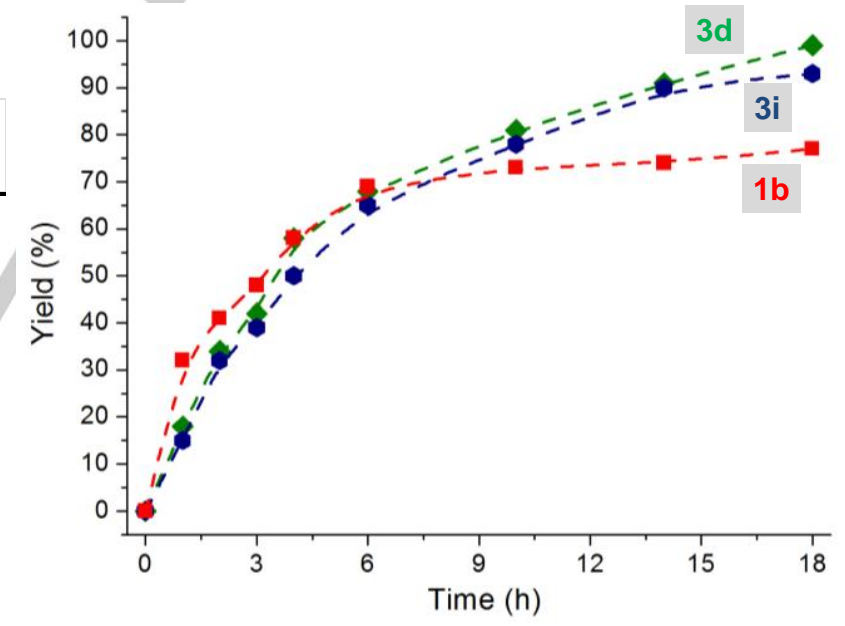

Figure 4. Comparative kinetics in the formation of carbonate $\mathbf{4 b}$ from 1,2 epoxyhexane and $\mathrm{CO}_{2}$ at $80^{\circ} \mathrm{C}$ using pyrogallol $\mathbf{1 b}$ (1.3 mol\%), resorcin[4]arene 3d $(0.50 \mathrm{~mol} \%)$ and pyrogallol[4]arene $3 \mathbf{i}(0.33 \mathrm{~mol} \%)$. Conditions used: $1,2-$ epoxyhexane $1.0 \mathrm{mmol}, \mathrm{NBu}_{4} \mathrm{l} 1.6 \mathrm{~mol} \%, 2.5 \mathrm{~mL}, p\left(\mathrm{CO}_{2}\right)^{\circ}=10 \mathrm{bar}, 80^{\circ} \mathrm{C}$. Note that in all reactions the same molar amount of phenol groups was used.

The influence of the time frame on the performance of the polyphenol to act as an efficient HB donor in the activation of epoxides was carried with resorcin[4]arene $\mathbf{3 d}$ and pyrogallol $\mathbf{1 b}$ in the synthesis of carbonate $\mathbf{4 b}$ (Table 4 ; scale $10 \mathrm{mmol}$ of $\mathbf{4 a}$ ). Solvent-less (neat) conditions were employed to favour kinetics and the use of nucleophile alone again showed considerably 
lower yield of $\mathbf{4 b}$ (entries 1 and 2; 7 and 32\%, respectively) compared with the use of both $\mathbf{3 d}$ and $\mathrm{NBu}_{4} \mathrm{l}$ combined (entries 2 and $4 ; 46$ and $74 \%$, respectively). Under these conditions, the TON based on the total of phenol active sites amounted to 1225 (entry 5). Higher turnover numbers were thus simply achieved by prolonging the reaction showing virtually full conversion after 30 h. The pyrogallol based catalyst (entries 6 and 7) showed lower efficiencies with only a modest increase in the TON as defined above after $18 \mathrm{~h}$ further confirming the favourable stability features of the cavitand structure $\mathbf{3} \mathbf{d}$ at elevated temperature. Thus the combination of the cooperative action of the resorcinol units in $\mathbf{3 d}$ with a higher chemical stability compared to pyrogallol 1b makes this system among the most efficient organocatalyst reported to date with very high TON. The turnover frequency of the binary catalyst system based on $\mathbf{3 d}$ and $\mathrm{NBu}_{4}$ I was estimated after $1 \mathrm{~h}$ (entry $3,46 \%$ ) considering the much lower conversion (entry 1, 7\%) in the absence of $\mathbf{3 d}$. When correcting for this background conversion still a significant part of it may be attributed to the binary catalyst $(39 \%, \mathrm{TON}=488$ based on phenol group molar concentration, TOF/h/[OH] group $\left.=488 \mathrm{~h}^{-1}\right)$, reporting thus the highest (initial) activity for a binary organocatalyst in this area.

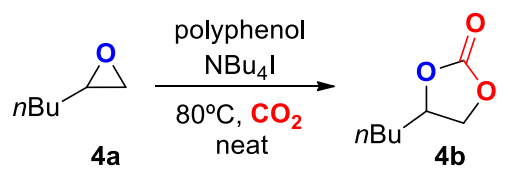

Table 4. Comparison between resorcin[4]arene $\mathbf{3 d} / \mathrm{NBu}_{4} \mathrm{I}$ and pyrogallol $\mathbf{1 b} /$ $\mathrm{NBu}_{4} \mathrm{l}$ as binary catalysts in the coupling of 1,2-epoxyhexane and $\mathrm{CO}_{2}$ at $80^{\circ} \mathrm{C}$ to afford cyclic carbonate $\mathbf{4 b}$. N.a. stand for non-applicable. ${ }^{[a]}$

\begin{tabular}{cccccccc}
\hline Entry & $\begin{array}{c}\text { Cat. } \\
{[\mathrm{mol} \%]} \\
{[\mathrm{a}]}\end{array}$ & $\begin{array}{c}\text { OH } \\
\text { units } \\
{[\mathrm{mol} \%]}\end{array}$ & $\begin{array}{c}\mathrm{t} \\
{[\mathrm{h}]}\end{array}$ & $\begin{array}{c}\text { Yield } \\
\mathbf{4 b} \\
{[\%]}\end{array}$ & $\begin{array}{c}\text { TON } \\
{[\mathrm{d}]}\end{array}$ & $\begin{array}{c}\text { TON }_{c} \\
{[\mathrm{e}]}\end{array}$ & $\begin{array}{c}\text { TOF }_{c} \\
{[\mathrm{f}]}\end{array}$ \\
\hline 1 & - & - & 1 & 7 & - & - & - \\
2 & - & - & 18 & 32 & - & - & - \\
3 & 3d, 0.010 & 0.080 & 1 & 46 & 575 & 488 & 488 \\
4 & 3d, 0.010 & 0.080 & 18 & 74 & 925 & 525 & 29 \\
5 & 3d, 0.010 & 0.080 & 30 & 98 & 1225 & n.a. & n.a. \\
6 & 1b, 0.026 & 0.080 & 18 & 60 & 750 & 350 & 19 \\
7 & 1b, 0.026 & 0.080 & 30 & 66 & 825 & n.a & n.a \\
\hline
\end{tabular}

[a] 1,2-epoxyhexane $10.0 \mathrm{mmol}$, polyphenol amount normalized with respect to $[\mathrm{OH}]$ groups (see third column), neat conditions, $p\left(\mathrm{CO}_{2}\right)^{\circ}=1.0 \mathrm{MPa}, \mathrm{NBu}_{4} \mathrm{I}$ $1.6 \mathrm{~mol} \%$. [b] Total amount of $\mathrm{OH}$ (phenol) units. [c] NMR yields based on mesitylene as internal standard, selectivity for $\mathbf{4 b}$ was $>99 \%$. [d] TON $=$ total turnover number based on molar amount of phenol groups. [e] Corrected TON using the measured background conversions, see entries 1 and 2. [f] Corrected average TOF/h using the measured background conversions, see entries 1 and 2 .

Motivated by these results, we then examined a wide scope of epoxide substrates (4a-22a) in the formation of their cyclic carbonates $\mathbf{4 b - 2 2 b}$ in the presence of $\mathrm{CO}_{2}$. In order to produce synthetically useful yields, $1.5-3.0 \mathrm{~mol} \%$ of $3 \mathbf{d}$ was used together with $5 \mathrm{~mol} \%$ of $\mathrm{NBu}_{4} \mathrm{X}(\mathrm{X}=\mathrm{I}, \mathrm{Br})$ in MEK $(2.5 \mathrm{~mL})$. The use of solvent was in some cases warranted to prevent solidification of the reaction mixture and incomplete conversion of the substrate: for the internal epoxides 18a-22a neat conditions were used.
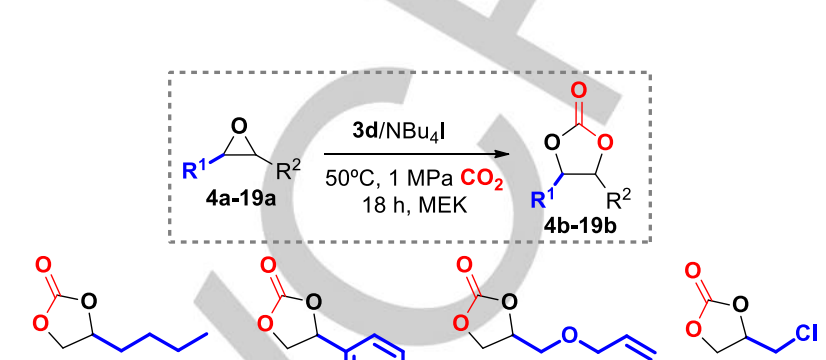

$4 \mathrm{~b}$

Conv. $>99 \%$ Yield: $94 \%$

O

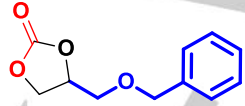
Conv. $>99 \%$ Yield: $95 \%$ O<smiles>C1=CC2COC2C1</smiles>

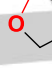

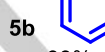
Conv. $>99 \%$ Yield: $93 \%$

0

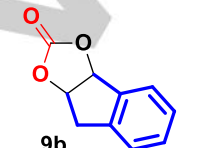

Conv. $>99 \%$ Yield: $97 \%$<smiles>CCCCCCC1COC(=O)O1</smiles>
13b Conv. $>99 \%$ Yield: $96 \%$

o

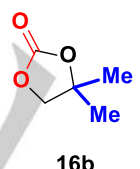

Conv. $>99 \%$

Yield: $94 \%$

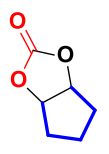

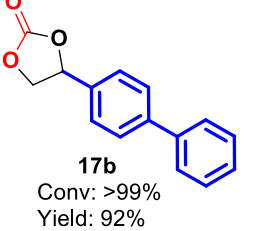

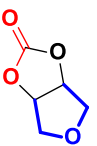

21b

Conv: $84 \%$

Yield: $79 \%^{*}$ cis $>99 \%$
Conv. $>99 \%$ Yield: $97 \%$

o<smiles>BrCC1COC(CBr)O1</smiles>

$10 \mathrm{~b}$

Conv. $>99 \%$ Yield: $99 \%$

O
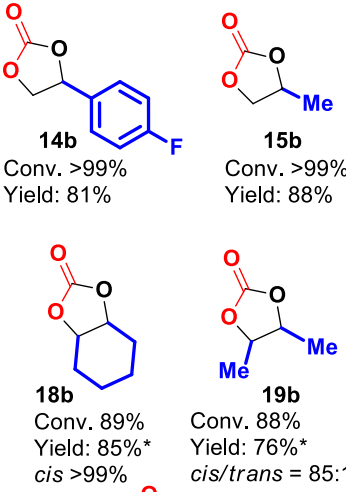

$19 \mathrm{~b}$

Conv. $88 \%$ o<smiles>C=C1O[C@@H](C)[C@@H](c2ccccc2)O1</smiles>

22b

Conv. $98 \%$

Yield: $92 \%{ }^{*}$

trans $>99 \%$
Figure 5. Substrate scope in the conversion of various terminal and internal epoxides $\mathbf{4 a - 2 2 a}$ into their cyclic carbonates $\mathbf{4 b} \mathbf{- 2 2} \mathbf{b}$ using $\mathbf{3 d} / \mathrm{NBu}_{4} \mathrm{l}$ as catalyst. General conditions: epoxide $1 \mathrm{mmol}, 1.5 \mathrm{~mol} \% 3 \mathrm{~d}, 5 \mathrm{~mol} \% \mathrm{NBu}_{4} \mathrm{l}, 18 \mathrm{~h}, 1 \mathrm{MPa}$, $50^{\circ} \mathrm{C}, 2.5 \mathrm{~mL}$ of MEK. ${ }^{*}$ Using $3 \mathrm{~mol} \%$ of $3 \mathrm{~d}, 5 \mathrm{~mol} \% \mathrm{NBu}_{4} \mathrm{Br}, 80^{\circ} \mathrm{C} 18 \mathrm{~h}$, neat.

At $50^{\circ} \mathrm{C}$ and $1 \mathrm{MPa}$ of pressure terminal epoxides $4 \mathrm{a}-17 \mathrm{a}$ were smoothly converted into their carbonates $\mathbf{4 b - 1 7 b}$ in high conversion (>99\%) and isolated yields (92-99\%). The temperature and pressure conditions are comparatively very mild considering the use of an organocatalyst system, and prompted us to examine more challenging internal epoxides (18a-22a) as reaction partners. To date limited progress has been achieved 
using such epoxide substrates in organocatalytic approaches. One promising example was recently reported by Tassaing et al. ${ }^{[12 b]}$ who used a fluorinated alcohol as HB donor and achieved at $100^{\circ} \mathrm{C}$ and $2 \mathrm{MPa}$ a conversion of $73 \%$ of cyclohexene oxide ( $\mathrm{CHO}$; 18a in Figure 5) after $5 \mathrm{~h}$. Werner et al. reported on the use of bifunctional phosphonium salts that were effective for internal epoxide conversion at temperatures in the range $90-120^{\circ} \mathrm{C}$ and 1 $\mathrm{MPa} \cdot{ }^{[10 a]}$ For $\mathrm{CHO}$ specifically, the best results in terms of yield were obtained at $120^{\circ} \mathrm{C}$ and $4 \mathrm{MPa}$ (40 bar) producing the carbonate $18 \mathrm{~b}$ in $69 \%$ yield after $6 \mathrm{~h}$.

We first screened potential conversion of $\mathrm{CHO} 18 \mathrm{a}$ at $50^{\circ} \mathrm{C}$ and $1 \mathrm{MPa}$ but this afforded the carbonate $18 \mathrm{~b}$ in only $6 \%$ yield after $18 \mathrm{~h}$. We were pleased to find that upon increasing the temperature to $80^{\circ} \mathrm{C}$ and using $3 \mathrm{~mol} \%$ of cavitand $3 \mathbf{d}$ the conversion of $18 \mathrm{~b}$ could be significantly increased to $89 \%$ (isolated yield $85 \%$ ) using neat conditions. As a control experiment, the reaction in the absence of $\mathbf{3 d}$ was also carried out and gave only $8 \%$ yield (duplo experiment) showing the importance of the cavitand $\mathbf{3 d}$ to achieve a high yield of $\mathbf{1 8 b}$ under similar conditions.

Other internal epoxides (19a-22a, Figure 5) were then also subjected to these latter conditions including cyclic and acyclic substrates. Whereas the 3,4-epoxyfuran 21a was converted in high conversion (84\%) and yield (79\%), the corresponding cyclopentene oxide 20a gave a much lower (reproducible) yield (38\%). The acyclic epoxides $19 a$ and 22 a were also converted into their carbonates $\mathbf{1 9 b}$ and $\mathbf{2 2 b}$ showing the more general potential of $\mathbf{3 d} / \mathrm{NBu}_{4} \mathrm{l}$ as a binary organocatalyst in the conversion of more challenging internal epoxides. All epoxides 18a-22a were converted with full retention of configuration (cis $>99 \%$ for $\mathbf{1 8 b}$, 20b and $\mathbf{2 1}$ b or trans $>99 \%$ for 22b) except for $\mathbf{1 9 a}$ (cis/trans = $8: 2$ ). Such loss of stereo-chemical information with this substrate in the formation of its carbonate product in the presence of $\mathrm{CO}_{2}$ has been observed before, ${ }^{[25]}$ and may be related to a partial $\mathrm{S}_{\mathrm{N}} 1$ character of the nucleophilic attack of the linear carbonate intermediate onto the $\mathrm{C}-\mathrm{Br}$ bond initially formed in the ringopening of the epoxide by $\mathrm{NBu}_{4} \mathrm{Br}$.

\section{Conclusions}

The use of easily accessible and modular cavitand structures such as resorcin[4]arenes and pyrogallol[4]arenes constitute interesting $\mathrm{HB}$ donor binary catalysts in combination with ammonium halide salts. The pre-organization of the phenolic units within the resorcin[4]arenes was proven to be beneficial for the catalytic efficiency in organic carbonate formation from epoxides and $\mathrm{CO}_{2}$, and resulted in cooperative effects (for $\mathbf{3 d}$ ) leading to significantly higher conversion rates compared to resorcinol $\mathbf{1 a}$. Upon raising the reaction temperature from 50 to $80^{\circ} \mathrm{C}$ in order to improve the overall reactivity, the cavitand structures showed higher chemical stability than pyrogallol $\mathbf{1 b}$ making these former systems more suitable for achieving both very high TONs. Also, resorcin[4]arene $\mathbf{3} \mathbf{d}$ combined with $\mathrm{NBu}_{4} \mathrm{l}$ shows very high initial turnover frequencies of almost $500 \mathrm{~h}^{-1}$ at $80^{\circ} \mathrm{C}$. This improved and unparalleled reactivity was shown to be beneficial in the formation of 19 different carbonates under comparatively mild reaction conditions $\left(50^{\circ} \mathrm{C}, 1 \mathrm{MPa}\right)$. Further to this, six di-substituted epoxides (16a and 18a-22a) were also screened as reaction partners and efficiently converted under neat conditions at $80^{\circ} \mathrm{C}$ providing good to excellent isolated yields of $79-94 \%$. Compared with the state-of-the-art in organocatalytic $\mathrm{CO}_{2}$ /epoxide coupling chemistry this is a remarkable result. Hence, cavitand based binary organocatalysts have proven to be sustainable, versatile and highly reactive alternatives for metal-based systems in the catalytic coupling of epoxides and $\mathrm{CO}_{2}$. Further attention is now on the combination of cooperative and bifunctional concepts to develop organocatalytic processes with improved reactivity under ambient conditions

\section{Experimental Section}

\section{General}

Methyl ethyl ketone (MEK, Aldrich ACS reagent >99\%) and carbon dioxide (purchased from PRAXAIR) were used as received without further purification or drying. All the resorcin[4]arenes and pyrogallol[4]arenes were synthesized following the classical condensation of aldehydes in the presence of acid. ${ }^{[18]}$ All other (polyphenolic) chemicals are commercially available at Aldrich and were used as received. ${ }^{1} \mathrm{H}$ and ${ }^{13} \mathrm{C}\left\{{ }^{1} \mathrm{H}\right\}$ NMR spectra were recorded on a Bruker Avance 500 NMR spectrometer at $297 \mathrm{~K}$. Chemical shifts are reported in ppm relative to the residual solvent peaks in $\mathrm{CDCl}_{3}(\delta=7.26 \mathrm{ppm})$ and [DMSO]-D 6 ( $\delta=2.50 \mathrm{ppm})$. Mass analyses were carried out by the High Resolution Mass Spectrometry Unit at the ICIQ in Tarragona, Spain.

\section{Cavitand synthesis}

Typical experiment: a solution of one equivalent of resorcinol/pyrogallol $(6 \mathrm{mmol})$ in a solution of ethanol $(95 \%, 75$ $\mathrm{mL})$ and concentrated hydrochloric acid $(25 \mathrm{~mL})$ was cooled to 2 ${ }^{\circ} \mathrm{C}$. Then the aldehyde reagent $(6 \mathrm{mmol}, 1$ eq. $)$ dissolved in ethanol $(95 \% 50 \mathrm{~mL})$ was added drop-wise to the reaction mixture. The resulting solution was stirred at $75^{\circ} \mathrm{C}$ during a period of $18 \mathrm{~h}$ up to $72 \mathrm{~h}$ depending on aldehyde substrate. Upon cooling to rt, the precipitate that separated was washed repeatedly with cold water and methanol and finally dried: the compounds were recrystalized from acetonitrile. Analysis details of all cavitand structures $\mathbf{3 a - 3} \mathbf{j}$ can be found in the Supporting Information.

\section{Catalytic experiments}

Typical procedure: the organic cyclic carbonate synthesis from epoxides and $\mathrm{CO}_{2}$ was carried out a $30 \mathrm{~mL}$ steel autoclave using 1,2-epoxyhexane $(1 \mathrm{mmol}, 1 \mathrm{eq})$, cavitand structure (1.0-1.5 $\mathrm{mol} \%), \mathrm{NBu}_{4} \mathrm{l}(5 \mathrm{~mol} \%)$ and MEK $(2.5 \mathrm{~mL})$. The autoclave was then subjected to three cycles of pressurization and depressurization with $\mathrm{CO}_{2}$. Finally the autoclave was charged with $1 \mathrm{MPa}$ (10 bar) of $\mathrm{CO}_{2}$, heated to $50^{\circ} \mathrm{C}$ and the content stirred for $18 \mathrm{~h}$. Hereafter, the autoclave was cooled to rt and carefully depressurized. The volatiles were removed under reduced 
pressure and the product was purified by flash column chromatography (1:1 hexane/ethyl acetate as eluent) to afford the pure cyclic carbonate. Analytical details of all organic carbonates $\mathbf{4 b - 2 2 b}$ can be found in the Supporting Information.

\section{Acknowledgements}

We thank ICIQ, ICREA, and the Spanish Ministerio de Economía y Competitividad (MINECO) through project CTQ-2014-60419-R and the Severo Ochoa Excellence Accreditation 2014-2018 through project SEV-2013-0319. Dr. Noemí Cabello, Sofía Arnal and Vanessa Martínez are acknowledged for the mass analyses. LMR thanks ICIQ for a predoctoral fellowship.

Keywords: carbon dioxide $\cdot$ cooperativity $\bullet$ organocatalysis • pyrogallenes $\cdot$ resorcinarenes

[1] For some general reviews: (a) M. Aresta, A. Dibenedetto, A. Angelini, Chem. Rev. 2014, 114, 1709-1742; (b) Q. Liu, L. Wu, R. Jackstell, M. Beller, Nat. Commun. 2015, 6, 5933; (c) M. Cokoja, C. Bruckmeier, B. Rieger, W. A. Herrmann, F. E. Kühn, Angew. Chem. Int. Ed. 2011, 50 8510-8537; (d) M. Peters, B. Köhler, W. Kuckshinrichs, W. Leitner, P. Markewitz, T. E. Müller, ChemSusChem 2011, 4, 1216-1240; (e) M. H. Beyzavi, C. J. Stephenson, Y. Liu, O. Karagiaridi, J. T. Hupp, O. K. Farha, Front. Energy Res. 2015, 2, 63. (f) R. Martín, A. W. Kleij, ChemSusChem 2011, 4, 1259-1263.

[2] (a) N. Kielland, C. J. Whiteoak, A. W. Kleij, Adv. Synth. Catal. 2013, 355, 2115-2138; (b) C. Martín, G. Fiorani, A. W. Kleij, ACS Catal. 2015, 5, 1353-1370; (c) Y. Tsuji, T. Fujihara, Chem. Commun. 2012, 48, 99569964; (d) B. Yu, L.-N. He, ChemSusChem 2015, 8, 52-62; (e) J. W. Comerford, I. D. V. Ingram, M. North, X. Wu, Green Chem. 2015, 17, 1966-1987.

[3] Selected examples: (a) M. R. Kember, P. D. Knight, P. T. R. Reung, C. K. Williams, Angew. Chem. Int. Ed. 2009, 48, 931-933; (b) M. A. Fuchs, C. Altesleben, S. C. Staudt, O. Walter, T. A. Zevaco, E. Dinjus, Catal. Sci. Technol. 2014, 4, 1658-1673; (c) A. Decortes, A. W. Kleij, ChemCatChem 2011, 3, 831-834; (d) A. Decortes, M. Martínez Belmonte, J. Benet-Buchholz, A. W. Kleij, Chem. Commun. 2010, 46, 4580-4582; (e) R. Ma, L.-N. He, Y.-B. Zhou, Green Chem. 2015, DOI: 10.1039/C5GC01826A; (f) O. Hauenstein, M. Reiter, S. Agarwal, B. Rieger, A. Greiner, Green Chem. 2015, DOI: 10.1039/C5GC01694K; (g) S. Kissling, M. W. Lehenmeier, P. T. Altenbuchner, A. Kronast, M. Reiter, P. Deglmann, U. B. Seemann, B. Rieger, Chem. Commun. 2015, 51, 4579-4582; (h) C. M. Byrne, S. D. Allen, E. B. Lobkovsky, G. W. Coates, J. Am. Chem. Soc. 2004, 126, 11404-11405; (i) M. A. Fuchs, S. Staudt, C. Altesleben, O. Walter, T. A. Zevaco, E. Dinjus, Dalton Trans. 2014 43, 2344-2347.

[4] Selected examples: (a) A. Buchard, M. R. Kember, K. G. Sandeman, C. K. Williams, Chem. Commun. 2011, 47, 212-214; (b) A. Buonerba, A. De Nisi, A. Grassi, S. Milione, C. Capacchione, S. Vagin, B. Rieger, Catal. Sci. Technol. 2015, 5, 118-123; (c) M. A. Fuchs, T. A. Zevaco, E. Ember, O. Walter, I. Held, E. Dinjus, M. Döring, Dalton Trans. 2013, 42, 5322 5329; (d) C. J. Whiteoak, E. Martin, M. Martínez Belmonte, J. BenetBuchholz, A. W. Kleij, Adv. Synth. Catal. 2012, 354, 469-476; (e) M. Taherimehr, S. M. Al-Amsyar, C. J. Whiteoak, A. W. Kleij, P. P. Pescarmona, Green Chem. 2013, 15, 3083-3090; (f) C.J. Whiteoak, E. Martin, E. Escudero-Adán, A. W. Kleij, Adv. Synth. Catal. 2013, 355 2233-2239; (g) X. Frogneux, O. Jacquet, T. Cantat, Catal. Sci. Technol. 2014, 50, 1529-1533.
[5] Selected examples: (a) T. A. Zevaco, A. Janssen, J. Sypien, E. Dinjus, Green Chem. 2005, 7, 659-666; (b) W. Clegg, R. Harrington, M. North, R. Pasquale, Chem. Eur. J. 2010, 16, 6828-6843; (c) J. Martínez, J. A. Castro-Osma, A. Earlam, C. Alonso-Moreno, A. Otero, A. Lara-Sánchez, M. North, A. Rodríguez-Diéguez, Chem. Eur. J. 2015, 21, 9850-9862; (d) J. A. Castro-Osma, M. North, X. Wu, Chem. Eur. J. 2014, 20, 15005 15008; (e) L. Peña Carrodeguas, J. González-Fabra, F. Castro-Gómez, C. Bo, A. W. Kleij, Chem. Eur. J. 2015, 21, 6115-6122; (f) V. Laserna, G. Fiorani, C. J. Whiteoak, E. Martin, E. Escudero-Adán, A. W. Kleij, Angew. Chem. Int. Ed. 2014, 53, 10416-10419; (g) C. J. Whiteoak, N. Kielland V. Laserna, E. C. Escudero-Adán, E. Martin, A. W. Kleij, J. Am. Chem. Soc. 2013, 135, 1228-1231; (h) Y. Qin, H. Guo, X. Sheng, X. Wang, F. Wang, Green Chem. 2015, 17, 2853-2858.

[6] Selected examples: (a) C. T. Cohen, T. Chu, G. W. Coates, J. Am. Chem. Soc. 2005, 127, 10869-10878; (b) G.-P. Wu, D. J. Darensbourg, X.-B. Lu, J. Am. Chem. Soc. 2012, 134, 17739-17745; (c) D. J. Darensbourg, S. J. Wilson, J. Am. Chem. Soc. 2011, 133, 18610-18613; (d) K. Nakano, S. Hashimoto, M. Nakamura, T. Kamada, K. Nozaki, Angew. Chem. Int. Ed. 2011, 50, 4868-4871; (e) M. R. Kember, A. J. P. White, C. K. Williams, Macromolecules 2010, 43, 2291-2298.

[7] (a) G. Fiorani, W. Guo, A. W. Kleij, Green Chem. 2015, 17, 1375-1389; (b) Dr. M. Cokoja, M. E. Wilhelm, M. H. Anthofer, W. A. Herrmann, F. E. Kühn, ChemSusChem 2015, 8, 2436-2454; (c) A. Tlili, E. Blondiaux, X. Frogneux, T. Cantat, Green Chem. 2015, 17, 157-168.

[8] (a) B. Chatelet, L. Joucla, J.-P. Dutasta, A. Martinez, K. C. Szeto, V. Dufaud, J. Am. Chem. Soc. 2013, 135, 5348-5351; (b) B. Chatelet, L. Joucla, J.-P. Dutasta, A. Martinez, V. Dufaud, Chem. Eur. J. 2014, 20 , 8571-8574.

[9] (a) S. Sopeña, G. Fiorani, C. Martín, A. W. Kleij, ChemSusChem 2015 8, 3248-3254; (b) C. J. Whiteoak, A. H. Henseler, C. Ayats, A. W. Kleij, M. A. Pericàs, Green Chem. 2014, 16, 1552-1559; (c) C. J. Whiteoak, A Nova, F. Maseras, A. W. Kleij, ChemSusChem 2012, 5, 2032-2038.

[10] (a) H. Büttner, J. Steinbauer, T. Werner, ChemSusChem 2015, 8, 26552669; (b) C. Kohrt, T. Werner, ChemSusChem 2015, 8, 2031-2034; (c) T. Werner, H. Büttner, ChemSusChem 2014, 7, 3268-3271.

[11] A. M. Hardman-Baldwin, A. E. Mattson, ChemSusChem 2014, 7, 32753278.

[12] (a) S. Gennen, M. Alves, R. Méreau, T. Tassaing, B. Gilbert, C Detrembleur, C. Jerome, B. Grignard, ChemSusChem 2015, 8, 1845 1849; (b) M. Alves, B. Grignard, S. Gennen, R. Mereau, C. Detrembleur, C. Jerome, T. Tassaing, Catal. Sci. Technol. 2015, 5, 4636-4643.

[13] A. Mirabaud, J.-C. Mulatier, A. Martinez, J.-P. Dutasta, V. Dufaud, ACS Catal. 2015, 5, 6748-6752

[14] H. Zhou, G.-X. Wang, W.-Z. Zhang, X.-B. Lu, ACS Catal. 2015, 5, 67736779.

[15] M. H. Anthofer, M. E. Wilhelm, M. Cokoja, M. Drees, W. A. Herrmann, F.E. Kühn, ChemCatChem 2015, 7, 94-98.

[16] Some illustrative examples of extended, functional cavitands: (a) A Gissot, J. Rebek, Jr., J. Am. Chem. Soc. 2004, 126, 7424-7425; (b) D. Ajami, J. Rebek, Jr. Nature. Chem. 2009, 1, 87-90; (c) L. MartínezRodríguez, N. A. G. Bandeira, C. Bo, A. W. Kleij, Chem. Eur. J. 2015, 21, 7144-7150.

[17] (a) L. R. MacGillivray, J. L. Atwood, Nature 1997, 389, 469-472; (b) L. Avram, Y. Cohen, J. Am. Chem. Soc. 2002, 124, 15148-15149.

[18] L. M. Tunstad, J. A. Tucker, E. Dalcanale, J. Weiser, J. A. Bryant, J. C. Sherman, R. C. Helgeson, C. B. Knobler, D. J. Cram, J. Org. Chem. 1989, 54, 1305-1312.

[19] The use of parent, non-functionalized cavitand structures in catalytic applications remains rare, see: Q. Zhang, K. Tiefenbacher, J. Am. Chem. Soc. 2013, 135, 16213-16219.

[20] Note that the Ph-substituted cavitand structure 3e showed incomplete dissolution in the reaction medium thereby affecting catalytic turnover. Larger R-groups are known to influence the preorganization of these structures and being thus beneficial for the selective formation of cavities; these effects are in particularly known and well-studied for related 
calix[4]arenes. Note also the recent work from Dufaud et al. (ref. 13) who reported on extended cavitands that can engage with tetraalky ammonium halides.

[21] L. Avram, Y. Cohen, Org. Lett. 2003, 5, 3329-3332.

[22] T. Gerkensmeier, J. Mattay, C. Näther, Chem. Eur. J. 2001, 7, 465-474.

[23] S.E. Blanco, M.C. Almandoz, F.H. Ferretti, Spectrochim. Acta: A 2005 61, 93-102.

[24] Dissociation Constants of Organic Acids in Aqueous Solution, eds. G. Kortum and K. Andrussow, International Union of Pure and Applied
Chemistry, Buttersworth, London (UK), 1961; Kim et al. used voltamettric measurement to determine the $\mathrm{p} K_{\mathrm{a}}$ (8.94) of pyrogallol, see: H.-S. Kim, T. D. Chung, H. Kim, J. Electroanal. Chem. 2001, 498, 209-215.

[25] (a) J. Langanke, L. Greiner, W. Leitner, Green Chem. 2013, 15, 11731182; (b) C. J. Whiteoak, E. Martin, E. Escudero-Adán, A. W. Kleij, Adv. Synth. Catal. 2013, 355, 2233-2239. 


\section{Entry for the Table of Contents:}

\section{FULL PAPER}

Organize yourself ! Cavitand based polyphenols in combination with $\mathrm{NBu}_{4} \mathrm{X}$ $(\mathrm{X}=\mathrm{I}, \mathrm{Br})$ are excellent organocatalysts for the synthesis of organic carbonates showing interesting cooperative behaviour and high chemical stability. The catalytic results demonstrate a combination of high initial TOFs with an exclusive substrate scope that includes several internal epoxides. These new metal-free, cheap and modular cavitand based binary catalysts showcase the importance of a pre-organization of functional groups for maximum catalytic efficiency.

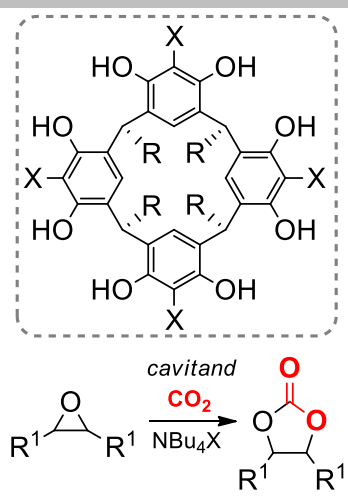

Luis Martínez-Rodríguez, Javier Otalora Garmilla and Arjan W. Kleij*

Page No. - Page No.

50-80 ${ }^{\circ} \mathrm{C}, 1 \mathrm{MPa}, 19$ examples - including internal epoxides - cooperative behavior \& robust o very high initial TOFs

\section{Cavitand based Polyphenols as} Highly Reactive Organocatalysts for the Coupling of Carbon Dioxide and Oxiranes 